\title{
CONTRIBUIÇÕES DA EXTENSÃO UNIVERSITÁRIA PARA UMA REFLEXÃO SOBRE SAÚDE, DESIGUALDADES SOCIAIS E VIOLÊNCIA: UM RELATO DE EXPERIÊNCIA
}

PAULO, C.A.S. ${ }^{1}$; SANTOS, L.S. ${ }^{2}$; PEREIRA, L.C.K. ${ }^{3}$; FRAGA, N.F. ${ }^{4}$; BORGES, R.A. ${ }^{5}$ \& GOMES, T.A.O. $^{6}$

${ }^{1}$ Doutor e Mestre em Política Social pela Universidade de Brasília (UnB). Professor Assistente da Universidade Federal do Recôncavo da Bahia (UFRB). Email: carlosalberto@ufrb.edu.br ; ${ }^{3}$ Bacharela em Saúde, pela Universidade Federal do Recôncavo da Bahia (UFRB). Email: luana_karam@ hotmail.com ; ${ }^{4}$ Bacharela em Saúde, pela Universidade Federal do Recôncavo da Bahia (UFRB).

luana_karam@hotmail.com. ${ }^{5}$ Graduanda do Bacharelado Interdisciplinar em Saúde, pela Universidade Federal do Recôncavo da Bahia (UFRB).nadylafraga@gmail.com

Artigo submetido em 04/03/2019

\section{RESUMO}

A extensão universitária se caracteriza como a relação entre a universidade e a comunidade a qual ela está inserida. Ao assumir a perspectiva do popular, a extensão passa a exercer um papel transformista no campo da saúde, desenvolvendo valores norteadores que visam a troca de saberes de ambas as partes, caracterizando o modelo pedagógico de Educação Popular proposto por Paulo Freire. Objetivou-se, assim, expor como a extensão universitária pode contribuir para a formação de profissionais de saúde, através de uma abordagem baseada na educação popular. Este estudo trata-se de um relato de experiência de caráter descritivo e analítico. Nele foi descrito o Módulo III: Diferenças sociais: Da desigualdade à violência, pertencente ao
Curso de Educação Popular em Saúde, ofertado para 22 educadores dos Espaços de Convivência e Fortalecimento de Vínculos (CRIAR) de um município do Recôncavo Baiano, em 2019. Para a realização do Módulo III foi feito uso de dinâmicas e exibição de vídeos, que mediaram as discussões acerca dos temas propostos: desigualdade social, saúde, privilégio e violência racial e de gênero. Os educadores demonstram resultado satisfatório. As ações extensionistas realizadas conseguiram cumprir sua missão de firmar o forte vínculo com a comunidade trabalhada, por meio da Educação Popular que suscitou uma abordagem mais efetiva. Diante disso, a Universidade foi capaz de cumprir seu papel de agente transformador da realidade.

PALAVRAS-CHAVE: Saúde. Desigualdade. Violência Social. Educação. Interdisciplinar.

\section{ACADEMIC CONTRIBUTIONS TO A REFLECTION ON HEALTH, SOCIAL INEQUALITIES AND VIOLENCE: AN EXPERIENCE REPORT}

\begin{abstract}
University extension is characterized as the relationship between the university and the community to which it is inserted. Taking the perspective of the popular, the extension starts to play a transforming role in the health field, developing guiding values that aim at the exchange of knowledge on both sides, characterizing the pedagogical model of Popular Education proposed by Paulo Freire. Thus, the objective was to expose how university extension can contribute to the training of health professionals, through an approach based on popular education. This study is a descriptive and analytical experience report. It described Module III: Social Differences: From Inequality to Violence, belonging to the Popular
\end{abstract}

Health Education Course, offered to 22 educators of Living and Bonding Spaces (CRIAR) in a municipality of Recôncavo Baiano, in 2019. To the realization of Module III was made use of dynamics and video exhibition, which mediated the discussions about the proposed themes: social inequality, health, privilege and racial and gender violence. The educators demonstrate satisfactory results. The extension actions carried out were able to fulfill their mission of establishing a strong bond with the working community, through Popular Education, which led to a more effective approach. Given this, the University was able to fulfill its role as a reality-transforming agent.

KEYWORDS: Design. Crafts. Clothing 


\section{INTRODUÇÃO}

Pensar a universidade como um espaço de compartilhamento de saberes, formação profissional e disseminação de conhecimento é um desafio diante da complexidade e diversidade do trabalho acadêmico. Segundo Rodrigues et. al. (2013), foi no século XIX, na Inglaterra, que surgiu a extensão, visando o direcionamento de novos caminhos para a sociedade, com a intenção de promover uma educação continuada. Nessa perspectiva a extensão universitária é caracterizada como uma relação entre a universidade e a comunidade na qual ela está inserida.

O Plano Nacional de Extensão, criado pelo Fórum de Pró-Reitores de Extensão das Universidades Públicas Brasileiras e pela Secretaria do Ensino Superior do Ministério da Educação e do Desporto, qualifica a extensão universitária como um processo educativo, cultural e científico conjuntando ensino e pesquisa, promovendo assim, uma relação transformista entre a universidade e a sociedade. "A extensão universitária ganha cada vez mais visibilidade no atual contexto, frente às inúmeras ações e atividades que visam atender a crescente demanda da sociedade por resoluções de problemas que muitas vezes não são atendidos pelas políticas públicas vigentes" (DEL-MASSO et. al., 2015, p. 2). Do mesmo modo, a extensão proporciona um saber diferenciado, devido à troca de conhecimento de ambas as partes, caracterizando o modelo pedagógico de Educação Popular proposto por Paulo Freire.

Ao assumir a perspectiva do popular, a extensão passa a considerar dimensões como: a origem e a direção das questões apresentadas; o componente político norteador das ações; e o popular fundamentado em metodologias que apontem seus aspectos éticos (dentre eles a tolerância e o coletivo) e utópicos (como autonomia e liberdade). Além disso, pode-se desenvolver outros valores norteadores de práticas extensionistas, que visem o compartilhamento de conhecimentos e atividades culturais, o respeito às diferenças e às escolhas individuais ou de grupos e a responsabilidade social (MELO, 2014).

Segundo o último Relatório de Desenvolvimento Humano (RDH) elaborado pelo Programa das Nações Unidas (2016), o Brasil ocupa o ranking entre os 10 países mais desiguais do mundo, num total de 140 países. Minayo (1999) evidencia que o Brasil aflige-se por extremas desigualdades, violência nos ambientes de trabalho, desemprego, exclusão social e moral, corrupção e impunidade. Estes são problemas que se arrastam historicamente no desenvolvimento do país e têm grande peso sobre a dinâmica da violência emergente e podemse associar estes fatores a persistente desigualdade de renda. 
A Organização Mundial de Saúde (2002) define que a violência é o uso de força ou poder em forma de ameaça ou efetivamente, contra si ou contra outras pessoas, podendo ocasionar lesão, morte, alterações do desenvolvimento, privações ou danos psíquicos. A saúde é o completo bem-estar físico, mental, social e espiritual (OMS, 2002), em vista disso, a violência encontra-se intimamente ligada a ela, pois a preservação de uma entra em detrimento com a outra. Minayo (1993) ressalta que a violência passa a ser objeto de reflexão da Saúde Pública, partindo da sua responsabilidade diante da morbi-mortalidade, que vitimiza crianças, jovens, adultos e idosos indiscriminadamente, podendo ser responsável por sérios agravos à saúde. Diante disto, é de fundamental importância a discussão desses temas, para a adoção de medidas que solucionem os problemas enfrentados no cotidiano da sociedade e consequentemente diminuam os índices da ocorrência dos mesmos.

Nesse contexto, o objetivo deste relato de experiência é expor como a extensão universitária, através de uma abordagem pedagógica baseada na educação popular, pode contribuir para a formação de profissionais de saúde que compreendam a determinação social do processo saúde-doença e sua relação com as desigualdades sociais e violência.

\section{MÉTODO}

O presente estudo trata-se de um relato de experiência de caráter descritivo e analítico. Nele, foi descrito a realização do Módulo III, Diferenças sociais: Da desigualdade à violência, realizado como parte do Curso de Educação Popular em Saúde, do componente curricular Processos de Apropriação da Realidade V (PAR V), do curso Bacharelado Interdisciplinar em Saúde (BIS), no Centro de Ciências da Saúde (CCS), da Universidade Federal do Recôncavo Baiano (UFRB), no município de Santo Antônio de Jesus-BA, em 2019.

O Bacharelado Interdisciplinar em Saúde é composto por cinco Unidades de Produção Pedagógica (UPP), definidas por temas direcionados pela grade curricular, como: Ser Humano e Realidade; Saúde, Cultura e Sociedade; Saúde e seus Determinantes; Saúde e Qualidade de Vida; Sistemas e Políticas de Saúde. Acrescentam-se a essa estrutura os eixos formados pelos módulos de Processos de Apropriação da Realidade (PAR), que se estende da UPP I até a UPP $\mathrm{V}$ e promovem a articulação entre ensino, pesquisa e extensão em comunidades de Santo Antônio de Jesus.

Os PARs foram componentes que se desenvolveram em contexto comunitário e integraram-se aos conteúdos aprendidos em sala de aula, proporcionando um desenvolvimento gradativo e contínuo entre os eixos. Eles possibilitaram a realização de atividades de pesquisa 
e extensão, de modo interdisciplinar, por meio do diálogo entre distintas áreas de conhecimento abordadas nas UPPs. Assim, o PAR V proporcionou, através do Curso de Educação Popular em Saúde, uma devolutiva à comunidade do Amparo/Andaiá, trabalhada durante as UPPs anteriores, mudando a perspectiva de trabalhar com um público jovem e passando a desenvolver os conhecimentos aprendidos na UPP V com um público adulto, compreendendo também, os outros Espaços CRIAR de Santo Antônio de Jesus.

Participaram do curso 22 pessoas, entre orientadores, coordenadora e equipe de apoio, que possuíam vínculos empregatícios com o Espaço de Convivência e Fortalecimento de Vínculos (CRIAR), um serviço financiado e promovido pelo município baiano de Santo Antônio de Jesus. As fontes de dados para construção deste relato foram as relatorias realizadas pela comissão de registros e a nossa observação participante.

O processo de construção do Curso de Educação Popular foi elaborado a partir das demandas relatadas pelos orientadores do Espaço CRIAR, a partir de um momento de sensibilização. Esta foi idealizada com o intuito de construir de forma coletiva, os temas que seriam abordados durante todo o curso. Também foram considerados os conhecimentos adquiridos através das experiências estudantis e vivências na comunidade do Andaiá/Amparo, assim como no CRIAR, durante os semestres passados. Desta forma, o curso foi construído não só como um instrumento de modificação social desses indivíduos, mas também como forma de compreensão da sua realidade, tendo como objetivo principal torná-los agentes de transformação social.

O curso foi dividido em quatro módulos e abordou os seguintes temas: O módulo I trouxe "SUS e SUAS: O que eu tenho a ver com isso?" fazendo referência aos direitos e deveres que os orientadores conheciam a respeito da sua profissão, bem como a sua compreensão sobre o seu papel dentro do Sistema Único de Saúde (SUS) e Sistema Único de Assistência Social (SUAS). O módulo II discorreu sobre "O ser educador”, que retratava sobre este papel dos orientadores sociais no espaço de convivência e fortalecimento de vínculos. O módulo III abordou sobre as "Diferenças sociais: Da desigualdade à violência”" com o objetivo de dialogar a relação entre as diversidades sociais, desigualdades e formas de violência. O módulo IV, o último, trouxe o tema “Como sujeitos de direito, qual é o meu papel social?”, que tinha o objetivo de mostrar aos orientadores do espaço CRIAR como eles podem ser agentes transformadores da sua realidade.

Cada módulo teve sua dinâmica de planejamento e desenvolvimento de acordo com os temas abordados. O módulo III foi construído em etapas e dividido em subtemas referentes ao 
tema principal, os tipos de violência, sendo: desigualdade social, impactos da violência à saúde, desigualdade racial e de gênero. Então, objetivou-se discutir a influência sociocultural no processo de construção das desigualdades, dialogar sobre questões de raça/cor no contexto atual, suscitar a análise das relações de gênero na sociedade brasileira e discutir sobre as diversidades no contexto social e sua influência nas situações de violência.

\section{RESULTADOS E DISCUSSÕES}

Inicialmente, ao chegar à sala em que aconteceu o curso, as cadeiras se encontravam em fileiras, organizadas com o padrão semelhante ao da educação bancária, logo os educadores demonstraram um estranhamento, uma vez que no módulo anterior eles aprenderam as características da Educação Popular, que se dá sem que haja uma hierarquia de lugar, geralmente em círculo, caracterizando uma aprendizagem horizontal.

O curso foi iniciado com uma "tempestade de ideias", como intuito reunir os conceitos prévios a respeito de Desigualdade e Violência e sua possível relação de causalidade, além de contribuir para o entrosamento com o grupo, uma vez que é uma técnica muito utilizada para enriquecer discussões e levantar reflexões. Diante disso, as palavras ditas por eles foram: "Exclusão, racismo, saúde, preconceito, discriminação, violação de direitos, vulnerabilidade, marginalização e negligência.”.

Com a sala ainda organizada em fileiras, foi executado o Jogo dos Privilégios. Um cesto de lixo foi colocado à frente da sala, o condutor explicou o jogo através da seguinte analogia: "Vocês representam a população de um país hipotético. E todo cidadão neste país tem a chance de crescer na vida, e pertencer às classes mais altas, [...] para subir às classes mais altas, tudo o que você precisa fazer é acertar sua bolinha de papel no cesto de lixo, sem se levantar da cadeira".

Após o estranhamento sobre a ideia do Jogo dos Privilégios, os educadores reconheceram que houve uma desigualdade, pois nem todos tiveram a mesma oportunidade de acertar a bola no cesto. Apenas 04 pessoas acertaram, podendo, assim, "subir na vida". Durante a discussão alguns integrantes do curso falaram que a renda familiar impacta diretamente no acesso à educação de qualidade e nas chances de entrar no nível superior. Ao questioná-los como se sentiram após a dinâmica, eles responderam que tiveram sentimento de revolta, pois as pessoas que estavam na frente acertaram a bola com mais facilidade, enquanto que as pessoas que estavam atrás não conseguiram acertar a bola na cesta, isto porque as pessoas da frente 
constituíram-se como um obstáculo e, consequentemente, uma posição de privilégio em relação a ela.

Após a introdução acerca de diferenças e desigualdades sociais, iniciou-se a discussão sobre raça, a partir da montagem de um quebra-cabeça. Ao todo foram 08 peças distribuídas aleatoriamente entre os educadores. Atrás de cada peça havia uma frase ou citação a respeito do tema (Quadro 01), a ideia central era que discussões e debates fossem feitos acerca da violência racial, pensando sua origem, permanência e consequências. E assim, ao passar de cada carta, o quebra-cabeça seria montado no meio da roda.

QUADRO 01: Dinâmica do quebra-cabeça

1. "Não sou descendente de escravos. Eu descendo de seres humanos que foram escravizados".

O que essa frase despertou em você? Como os processos históricos refletem nas relações dos dias de hoje?

2. "Raça, referindo-se a seres humanos, é um termo que foi utilizado historicamente para identificar categorias humanas socialmente definidas, que se diferem, por exemplo, em cor da pele ou tipo de cabelo."

3. "Etnia refere-se a um grupo de pessoas que compartilham de uma mesma língua, religião, cultura, mesmas tradições, território ou mesmas condições históricas.”

4. O que é preconceito? E racismo?

5. Pense numa pessoa bonita. Como ela é? Qual o padrão de beleza brasileiro?

6. "Lista negra"; "Dia de branco"; "Cabelo duro"; "Ter uma neguinha"... O que esses termos significam pra você?

7. "É pelo corpo que se reconhece a verdadeira negra." Comente.

8. "Ninguém nasce odiando outra pessoa pela cor de sua pele, por sua origem ou ainda por sua religião. Para odiar, as pessoas precisam aprender, e se podem aprender a odiar, elas podem ser ensinadas a amar." O que você acha dessa frase?

Fonte: elaborado pelos autores

A utilização de peças de quebra-cabeça com frases norteadoras foi eficaz para os debates sobre raça. Os educadores demonstraram gostar da ideia e apesar de inicialmente ficarem com um pouco de receio para aceitar as cartas e dar sua visão sobre as mesmas, com o tempo foram se entrosando, colaborando para o surgimento de discussões e falas provocativas no decorrer da dinâmica. 


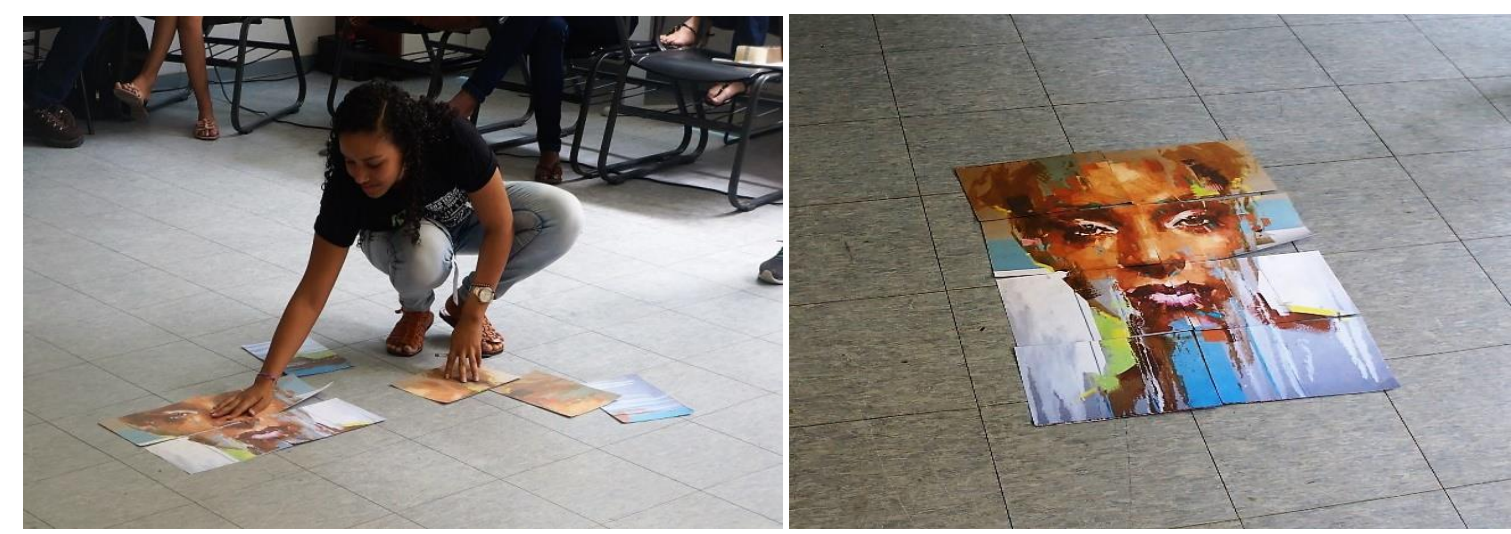

FIGURAS 01 e 02: Registro da montagem do quebra-cabeça durante a dinâmica sobre desigualdade racial.

Várias foram as discussões levantadas em torno das cartas, como a leitura da carta 4 (Quadro 01), na qual uma cascata de opiniões e experiências foram relatadas. Um dos educadores disse que "existem pessoas que não são empoderadas e se submetem a situações racistas passivamente", desenvolvendo um debate sobre como o empoderamento repercute, principalmente, nas crianças. Foi relatado como o tratamento diferenciado para crianças impacta emocionalmente nas suas vidas e quando a criança é negra este fator é mais visível. Também, foi analisado que as crianças negras já sofrem cotidianamente violências e quando essas violências são reforçadas, quando são postas em comparação com outras crianças, da mesma cor ou brancas, isso impacta fortemente e negativamente para eles.

Um material educativo da UNICEF (2010), sobre os efeitos do racismo na infância, relata estudos apontando que ainda na primeira infância, a criança consegue notar diferenças na aparência das pessoas, como a cor da pele. Por isso, é de suma importância que os adultos assumam a responsabilidade e evite orientações preconceituosas nesse momento. Quando uma criança vive em uma realidade de desigualdade e de discriminação acaba por ter a ilusão de que as pessoas devem ocupar lugares diferentes na sociedade, segundo sua cor de pele e aparência. Assim, este estudo acredita que uma criança pode achar prejudicial ter nascido negra ou indígena ou pertencer a um grupo étnico-racial mais discriminado. "Os efeitos disso são a negação e o esquecimento de suas histórias e culturas." (UNICEF, 2010).

A última carta trazia uma frase do ex-presidente da África do Sul, Nelson Mandela, a qual todos concordaram e realmente demonstraram acreditar no sentido desta, enfatizando que realmente se as pessoas "podem aprender a odiar, elas podem ser ensinadas a amar". Além disso, foi apresentado o vídeo 2 minutos para entender - Desigualdade Racial no Brasil, que expõe como o fato de ser branco ou negro influencia a vida da população brasileira, tanto na educação, quanto classe socioeconômica, qualidade de vida e tempo de vida desses indivíduos. 
Algumas opiniões demonstraram divergências, entretanto nenhum educador foi julgado ou mal interpretado, todos foram ouvidos e tiveram suas opiniões respeitadas, sendo ativos, participativos e atores principais de todo o processo da dinâmica. Todos os presentes demonstraram estar aprendendo algo, assim como também tinham algo para ensinar, acabando por retratar assim, um dos sentidos mais importantes da Educação Popular. Ao final da montagem do quebra-cabeça, o rosto de uma mulher negra foi formado, levando a uma salva de palmas e abrindo oportunidade para iniciar a segunda temática, gênero.

Após um intervalo para o lanche, o curso retornou com o propósito de discutir o modo como as expectativas sociais relativas ao comportamento que se espera de uma mulher ou um homem, ou seja, os estereótipos de gênero moldam as nossas definições de masculino e feminino. Para tal, foi aplicada a Dinâmica da Bola, onde o grupo se organizou em círculo e foram elencado um por vez para segurar a bola. Os escolhidos tinham que responder uma das duas perguntas da dinâmica: "Mulher é?" ou "Homem é?", rapidamente, sendo que a pergunta era, aleatoriamente, escolhida e feita pelo condutor. Uma tabela contendo duas colunas: "Mulher é" e "Homem é", foi montada no quadro e preenchida pelas respostas dos educadores.

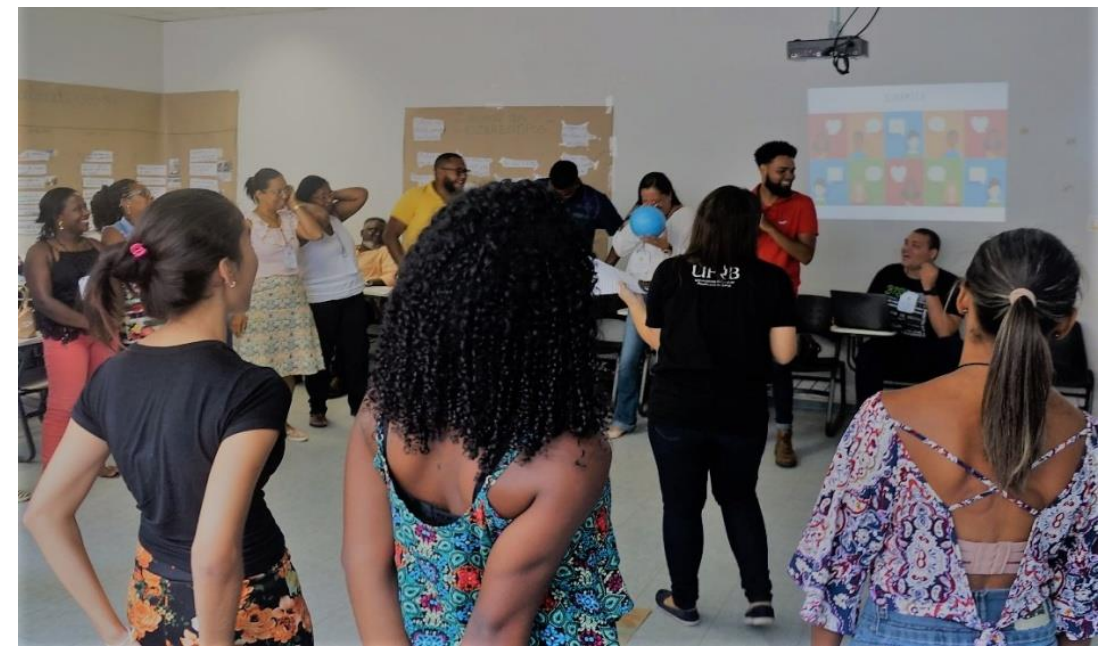

FIGURA 03: Registro durante a dinâmica da bola sobre desigualdades de gênero

As respostas foram: "Homem é..." - privilegiado, resistente, inteligente, esperto, sábio, intelectual, massa, companheiro, sabido, forte, mandão, articuloso, provedor, alto, grande, sarado, alegre. "Mulher é..." - frágil, forte, fêmea, dona da vida, bonita, resistente, alegre, inteligente, delicada, sábia, guerreira, dona de casa, maravilhosa, feliz, linda. Posteriormente, houve uma discussão interessante sobre igualdade de gênero, em que os educadores trouxeram suas vivências e suas opiniões em relação ao tema, bem como aspectos religiosos que norteiam seus argumentos. Para complementar, também foi trazida a questão da saúde do homem, em 
relação aos horários de funcionamento das unidades de saúde, nos períodos em que a maioria dos homens estão trabalhando, além da própria negligência masculina em buscar o serviço de saúde devido à estereótipos que associam a figura masculina à fragilidade, o que foi trazido por eles: "As mulheres vivem mais que os homens porque se cuidam mais". Além disso, também se discutiu as diferenças biológicas entre homens e mulheres, que apesar de haver uma diferença de condicionamento físico, isso não os impedem de desempenhar as mesmas funções: "Eu acho bonito quando o homem faz o papel que a mulher também faz".

Após essas falas sobre papéis de homens e mulheres, foi questionado se eles realmente existem, ou se são apenas impostos pela sociedade, e nesse momento houve uma discordância entre o grupo, uma vez que uns concordaram que não existem papéis determinados para homens e mulheres, "Eu tenho uma filha e moro só com minha filha. Sou o pai e mãe dela." Enquanto outros, baseados em suas crenças afirmaram acreditar que os papéis de homem e mulher são determinados. "Nos foi ensinado e a bíblia também nos ensina que o homem provê e a mulher cria os filhos."

Por fim, a mensagem trazida no módulo foi transmitida com êxito, ressaltando que as diferenças entre homens e mulheres existem, tanto do ponto de vista social como biológico. No entanto, essas diferenças não podem ser usadas para gerar a desigualdade e devem ser levadas em conta através do princípio da equidade.

Após a dinâmica, o tema "Desigualdade de Gênero" foi discutido entre o grupo, e eles trouxeram casos que já vivenciaram para exemplificar tal questão. Além disso, foi feita a exibição do vídeo "O Desafio da Igualdade”, para exemplificar as diferenças de gênero que são impostas desde criança. Trata-se de uma campanha que visa à conscientização para a desconstrução de paradigmas e estereótipos desde a infância e ilustra como diferenças de gênero são traçadas culturalmente e não biologicamente, como as capacidades de cada gênero são definidas a partir do sexo biológico e como isso influencia na desigualdade, que propicia a violência de gênero.

Para classificar os principais fatores sociais que geram violência, foi realizada a construção de um ecomapa (Figura 04), juntamente com os educadores. Esse instrumento é utilizado como recurso pedagógico que auxilia na identificação e caracterização do contexto social em que um indivíduo está inserido, analisando assim as situações de vulnerabilidade por ele sofrida e como isso colabora para os processos de desigualdade que pode estar afetando-o. 
FIGURA 04: Modelo de Ecomapa Social

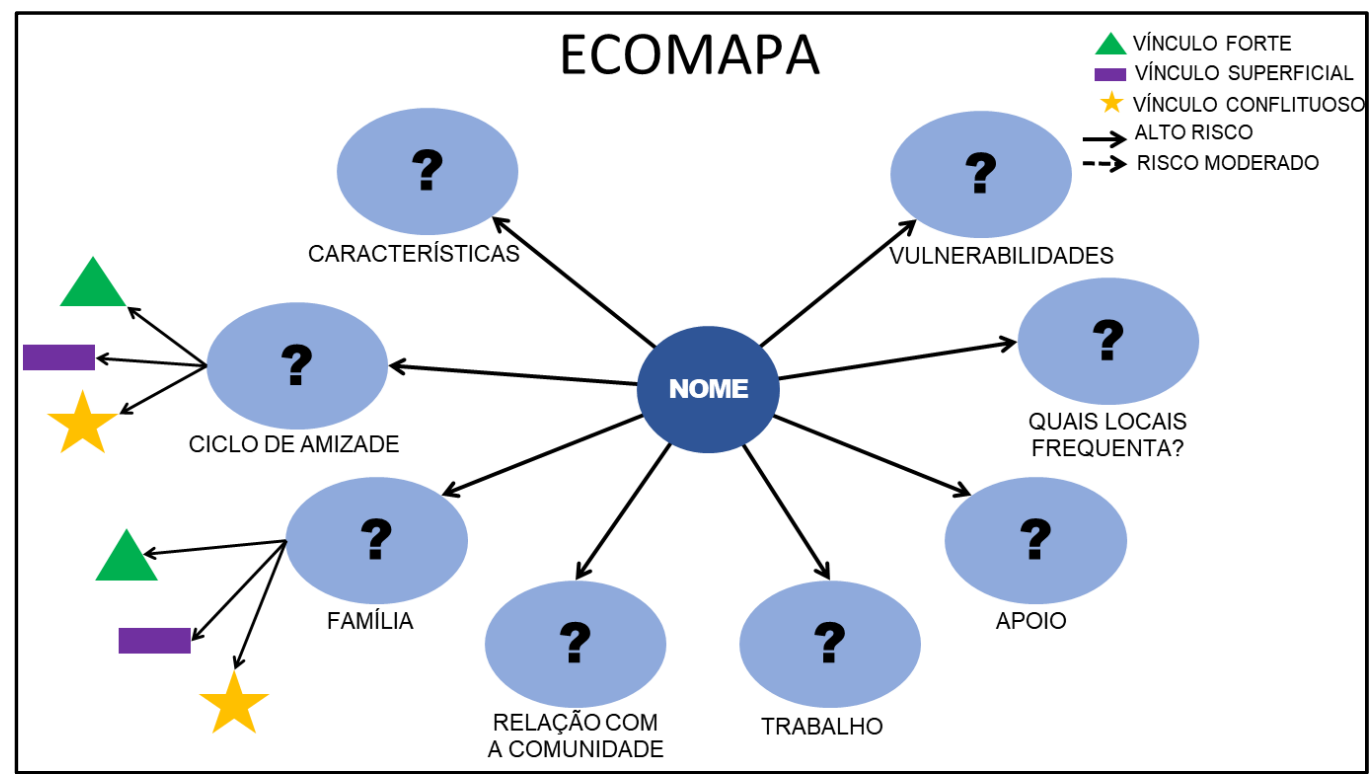

Fonte: elaborado pelos autores

Para finalizar, foi lido um cordel sobre Intolerância, do escritor Bráulio Bessa (2017), que traz uma visão lúdica sobre respeitar, para ser respeitado. Assim ele diz, "Seja menos preconceito! Seja mais amor no peito! E se não der pra ser amor; seja pelo menos respeito!”.

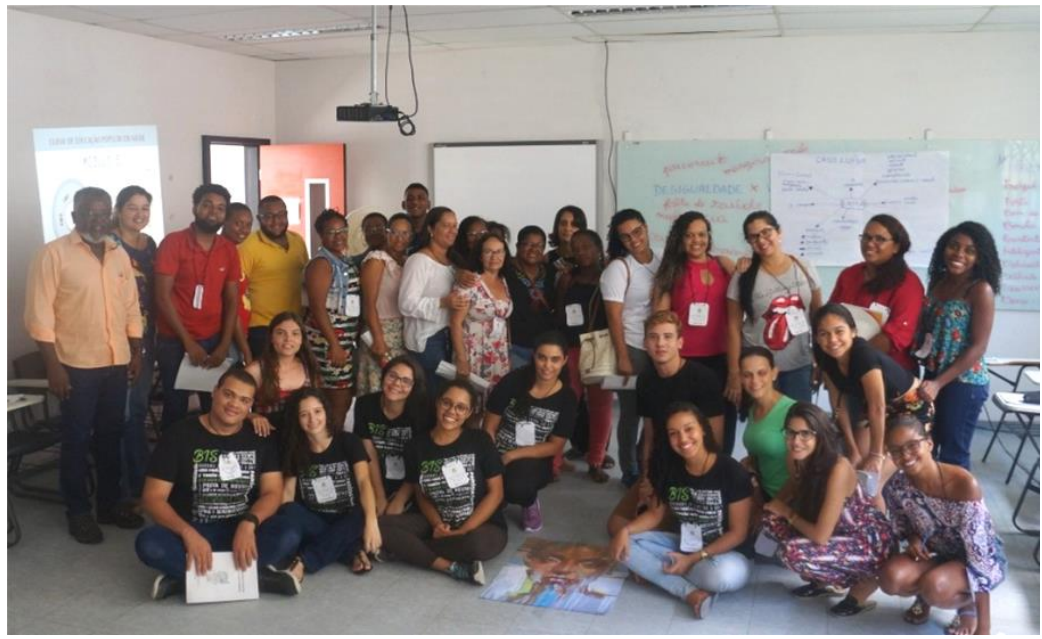

FIGURA 05: Registro dos participantes reunidos após a finalização do curso, no CCS.

\section{CONSIDERAÇÕES FINAIS}

O princípio da educação popular foi de suma importância para o êxito do módulo III do curso de Educação Popular em Saúde. O processo de construção, a partir das demandas apresentadas por eles, possibilitou o diálogo com os educadores e a aproximação mais efetiva à realidade dos mesmos, nos propiciando vivenciar as bases da educação freiriana.

De acordo com Leite et. al. (2014, p.1569), “A Educação Popular tem reorientado não só o processo de ensino-aprendizagem ou a relação educador-educando, mas tem contribuído 
significativamente na maneira como os indivíduos - que a conhecem e a vivenciam posicionam-se e relacionam-se com o mundo e em sociedade.” Pode-se dizer, portanto, que a Educação Popular possibilita ampliar a área da educação, englobando e articulando também temas como violência, desigualdade social e saúde. Desta forma, é notória a importância de instituir uma comunicação entre a educação popular e a questão social, direcionando esta para uma visão que envolve um conjunto de desigualdades, proporcionando assim, um pensar abrangente nos processos que a desencadeiam.

Conclui-se então, que a abordagem do módulo Diferenças sociais: Da desigualdade à violência do Curso de Educação Popular em Saúde foi efetiva, uma vez que a Universidade pôde cumprir o seu papel de agente transformador social e a extensão favoreceu a construção de um vínculo sólido de aproximação e troca de saberes entre a comunidade e a academia.

\section{REFERÊNCIAS}

DEL-MASSO, Maria Candida Soares et al. Extensão universitária e as demandas sociais.

Revista Ciência em Extensão, v. 11, n. 1, p. 2-7, 2015. Disponivel em:

http://ojs.unesp.br/index.php/revista_proex/article/view/1247

JĀHĀNA, Selima. Human development report 2016: human development for everyone. United Nations Publications, 2016. Disponível em:

http://hdr.undp.org/sites/default/files/2016_human_development_report.pdf

LEITE, Maria Francilene et al. Extensão Popular na formação profissional em saúde para o SUS: refletindo uma experiência. Interface-Comunicação, Saúde, Educação, v. 18, p. 15691578, 2014. Disponível em: https://doi.org/10.1590/1807-57622013.04.

MELO, José Francisco de. Extensão popular / José Francisco de Melo. 2.ed. - João Pessoa: Editora da UFPB, 2014. 122p. Disponível em: http://www.ccm.ufpb.br/redepopsaude/wpcontent/uploads/2016/06/Extensão-Popular.pdf

MINAYO, Maria Cecília de S.; SOUZA, Edinilsa R. de. Violência para todos. Cadernos de Saúde Pública, v. 9, p. 65-78, 1993. Disponível em:

https://www.scielosp.org/pdf/csp/1993.v9n1/65-78/pt

MINAYO, Maria Cecília de Souza; SOUZA, Edinilsa Ramos de. É possível prevenir a violência? Reflexões a partir do campo da saúde pública. Ciência \& Saúde Coletiva, v. 4, p. 7-23, 1999. Disponível em: https://www.scielosp.org/pdf/csc/1999.v4n1/7-23/pt

ORGANIZAÇÃO MUNDIAL DA SAÚDE; KRUG, Etienne G. Relatório mundial sobre violência e saúde. Genebra: Organização Mundial da Saúde, 2002. Disponível em: http://portal.pmf.sc.gov.br/arquivos/arquivos/doc/01_03_2010_9.48.45.b08c211d429981fb38 56eaf7ec4807b1.doc

RODRIGUES, Andréia Lilian Lima et al. Contribuições da extensão universitária na sociedade. Caderno de Graduação-Ciências Humanas e Sociais-UNIT, v. 1, n. 2, p. 141- 
148, 2013. Disponível em:

https://periodicos.set.edu.br/index.php/cadernohumanas/article/view/494/254

United Nations Children's Fund (UNICEF). O impacto do racismo na infância. Brasília. 2010. Disponível em: 〈https://www.unicef.org/brazil/pt/br_folderraci.pdf >

Universidade Federal do Recôncavo da Bahia (UFRB). Projeto Pedagógico do Curso do Bacharelado Interdisciplinar em Saúde (BIS). Portaria N 890/2014. Cruz das Almas: 2016. Disponível em: <https://www.ufrb.edu.br/ccs/images/AscomCCS/BIS/PPC/PPC-BIS--2017.pdf> 